\title{
Grain-Boundary Grooving of Plasma-Sprayed Yttria-Stabilized Zirconia Thermal Barrier Coatings
}

\author{
Kendra A. Erk, ${ }^{*}$ Christophe Deschaseaux, and Rodney W. Trice ${ }^{\star,}$ \\ Purdue University, School of Materials Engineering, West Lafayette, Indiana 47907
}

\begin{abstract}
The focus of this study was to determine the mechanisms responsible for the microstructural changes of plasma-sprayed 7 wt $\% \mathrm{Y}_{2} \mathrm{O}_{3}-\mathrm{ZrO}_{2}$ thermal barrier coatings with annealing from $800^{\circ}$ to $1400^{\circ} \mathrm{C}$. Mullins's thermal grooving theories have been applied to plasma-sprayed TBCs to determine the dominant mass transport mechanism at various temperatures. Grainboundary groove widths were measured as a function of annealing time and temperature using atomic force microscopy (AFM). The same collection of grains was analyzed after progressive heat treatments. Surface diffusion was found to be the dominant diffusion mechanism at $1000^{\circ} \mathrm{C}$, corresponding to the disappearance of intralamellar cracks at that temperature. At $1100^{\circ} \mathrm{C}$, both surface and volume diffusion were active. Volume diffusion, found to be the dominant diffusion mechanism at $1200 \mathrm{C}$ and above, was responsible for the sintering of interlamellar pores observed from AFM analysis of a single, progressively heat-treated interlamellar boundary. Surface roughening was observed to coarsen with increased annealing time and disappear with increased annealing temperature.
\end{abstract}

\section{Introduction}

$\mathrm{P}$ LASMA-SPRAYED ceramic thermal barrier coatings (TBCs) are widely used to protect the metallic components of gas turbine engines and improve operating efficiencies by permitting higher operating temperatures and reduced cooling requirements. TBC systems are comprised of a yttria-stabilized zirconia (YSZ) top coat with a composition of $6-8 \mathrm{wt} \% \mathrm{Y}_{2} \mathrm{O}_{3}-\mathrm{ZrO}_{2}$ plasma sprayed over a metallic bond coat. A MCrAlY ( $\mathrm{M}$ being either $\mathrm{Ni}, \mathrm{Co}$, or $\mathrm{Fe}$ ) bond coat is often used to facilitate strong adhesion between the YSZ and metallic component (such as a turbine blade). ${ }^{1}$ The temperature experienced at the surface of the structure has been shown to decrease by $189^{\circ} \mathrm{C}$ for a YSZ coating $127 \mu \mathrm{m}$ thick. $^{2}$

Plasma spraying of YSZ powders results in a complex microstructure. ${ }^{1,3,4}$ As droplets of molten YSZ strike the substrate at high velocity, they spread to form flattened discs. Coatings are made of multiple stacked discs, termed lamellae. The large thermal gradient between the relatively cool substrate and the newly sprayed lamellae causes directional solidification at a cooling rate in the range of $10^{4}-10^{6} \mathrm{~K} / \mathrm{s},{ }^{3,4}$ resulting in a columnar grain structure within each lamella. The columnar grains, oriented perpendicular to the substrate, are clearly resolved on transmission electron micrographs. ${ }^{5,6}$ Intralamellar cracking occurs perpendicular to the substrate upon cooling to relieve thermal stresses. ${ }^{7}$ Total porosity of plasma-sprayed ceramic coatings is typically between $3 \%$ and $20 \%$; high porosity is advantageous as it acts to reduce thermal conductivity of the coating. ${ }^{1}$ Total

G. Rohrer-contributing editor

Manuscript No. 20837. Received August 3, 2005; approved December 12, 2005. This work was supported by the National Science Foundation under contract no. 0134286-DMR.

${ }^{*}$ Member, American Ceramic Society.

${ }^{\dagger}$ Author to whom correspondence should be addressed. e-mail: rtrice@purdue.edu porosity is comprised of two main types: porosity between lamellae (i.e., interlamellar pores) and porosity within lamellae (i.e., intralamellar pores). ${ }^{3}$ The greatest amount of porosity is attributed to interlamellar pores, which are oriented perpendicular to the spray direction. ${ }^{4}$

The rapid cooling rates achieved during plasma spraying prevent the diffusion of yttrium cations $\left(\mathrm{Y}^{3+}\right)$ during solidification, resulting in the formation of a non-transformable yttrium-rich tetragonal phase designated here as $t^{\prime}-\mathrm{ZrO}_{2}{ }^{8,9}$ Non-transformable zirconia is a non-equilibrium phase as the concentration of yttrium cations in the zirconia lattice is greater than the concentration predicted by the $\mathrm{ZrO}_{2}-\mathrm{Y}_{2} \mathrm{O}_{3}$ phase diagram. ${ }^{10}$ Thus, $t^{\prime}-\mathrm{ZrO}_{2}$ is unstable at high temperatures. ${ }^{9}$

As plasma-sprayed YSZ coatings are exposed to temperatures simulating the service conditions in an engine $\left(800^{\circ}-\right.$ $1300^{\circ} \mathrm{C}$ ), numerous microstructural changes occur that greatly affect the material properties of the coatings. ${ }^{11}$ Morphological changes lead to increases in thermal conductivity. Ilavsky et al. ${ }^{12}$ used small angle neutron scattering (SANS) to analyze the shape of microstructural defects present in YSZ coatings as a function of temperature. Healing of intralamellar microcracks was found to begin around $800^{\circ} \mathrm{C}$. Microcracks continued to close with increasing temperature and were fully closed at $1000^{\circ} \mathrm{C}$. Additionally, at temperatures above $1000^{\circ} \mathrm{C}$, surface area attributed to interlamellar porosity began to decrease. The different sintering regimes were believed to be related to the size and shape of the voids. ${ }^{13}$ Trice et al. ${ }^{6}$ presented visual confirmation of intralamellar microcrack and interlamellar pore disappearance (after $1000^{\circ} \mathrm{C} / 50 \mathrm{~h}$ and $1200^{\circ} / 50 \mathrm{~h}$ heat treatments, respectively) which was linked to the observed increase in thermal conductivity of the coatings.

Although the microstructural evolution adversely affecting the properties of thermal barrier coatings during service at high temperatures is well documented, the mechanisms responsible for these microstructural changes remain unclear. The purpose of the present study is to investigate the mechanisms responsible for the microstructural changes of plasma-sprayed YSZ coatings during heat treatment. Atomic force microscopy (AFM) is used to observe grain-boundary grooving, observe interlamellar porosity evolution, and determine the dominant diffusion mechanism at certain temperatures by Mullins's thermal grooving theories. ${ }^{13,14}$ The shrinkage behavior of cylindrical stand-alone coatings, indicative of coating densification, is investigated using dilatometry to confirm the AFM dominant diffusion mechanism results.

\section{Experimental Procedure}

\section{(1) Sample Preparation}

The YSZ powder used in the processing of all plasma-sprayed coatings in this study had a nominal composition of $7 \mathrm{wt} \%$ $\mathrm{Y}_{2} \mathrm{O}_{3}$ and $93 \mathrm{wt} \% \mathrm{ZrO}_{2}$, with an average particle size of $22 \mu \mathrm{m}$ (Amperit 825.0, H.C. Starck, Newton, MA). It was a fused and crushed powder. The coatings were plasma sprayed at two different locations, though similar spraying parameters were used. $^{15}$ 
The YSZ specimen used for AFM analysis was plasma sprayed at Ames National Laboratory with a SG-100 plasma spray gun (Praxair, Danbury, CT) mounted to a two-way stage. The YSZ was sprayed directly onto a flat copper substrate to a thickness of approximately $2 \mathrm{~mm}$. The coating surface was ground and sectioned into samples roughly $10 \mathrm{~mm}$ long and 5 $\mathrm{mm}$ wide using a diamond-coated blade. The copper substrate was dissolved by immersion in a strong nitric acid solution. The sample surface to be analyzed was coarse ground on a $14 \mu \mathrm{m}$ $\mathrm{SiC}$ polishing wheel and progressed through finer polishing media until a final polishing suspension of $0.05 \mu \mathrm{m}$ chrome oxide particles was used. The coating specimen used for the AFM studies had a bulk density of $5.5 \mathrm{~g} / \mathrm{cm}^{3}$ with average total porosity of $9.4 \% .^{15,16}$

Specimens used for dilatometry were sprayed at Northwestern University in Evanston, IL, using a small particle plasmaspray injector. ${ }^{17}$ A $100-200 \mu \mathrm{m}$ thick aluminum layer was sprayed uniformly onto a rotating alumina tube $(300 \mathrm{~mm}$ long and $13 \mathrm{~mm}$ in diameter), on top of which YSZ was sprayed to a thickness of approximately $200-300 \mu \mathrm{m}$. Each sprayed rod was cut into approximately $15 \mathrm{~mm}$ long samples. The edges of the sample were machined on a lathe using a diamond tool, so that the faces of each section were parallel. The intermediate aluminum layer was dissolved in a weak solution of hydrochloric acid, releasing the YSZ coating from the substrate. The final dimensions of each sample were nominally $13 \mathrm{~mm}$ tall with a wall thickness of $250 \mu \mathrm{m}$. The bulk density of the tubes was $5.0 \mathrm{~g} / \mathrm{cm}^{3}$ with an average total porosity of approximately $17.1 \%$, calculated assuming the theoretical density of YSZ to be $6.08 \mathrm{~g} /$ $\mathrm{cm}^{3} .15,16$

\section{(2) AFM Analysis and Theory}

The topography and microstructural evolution of YSZ coatings was investigated as a function of heat-treatment temperature and time using a MultiMode AFM (Digital Instruments, Santa Barbara, CA) in tapping mode. PointProbe ${ }^{\circledR}$ Plus silicon AFM probes (Nanosensors ${ }^{\mathrm{TM}}$, Neuchatel, Switzerland) having a probe tip radius $<10 \mathrm{~nm}$ were used. Polished coating samples were scanned to quantify initial surface roughness before heating. Coatings were isothermally etched in air for $1-100 \mathrm{~h}$ at temperatures ranging from $800^{\circ}$ to $1400^{\circ} \mathrm{C}$ in a programmable Lindberg box furnace. Heating and cooling rates were $600^{\circ}$ and $300^{\circ} \mathrm{C} / \mathrm{h}$, respectively. To provide a barrier to furnace contaminants, the coatings were contained in a covered alumina crucible. After each heat treatment, AFM area scans 4,9 , or $25 \mu \mathrm{m}^{2}$ in size were taken, corresponding to lateral resolutions of \pm 4 , \pm 6 , or $\pm 10 \mathrm{~nm}$, respectively. Two separate studies were performed: grain-boundary widths were measured from plane-view coating scans, and interlamellar porosity and grain structure evolution were studied from cross-sectional coating scans.

In the first AFM study, grain-boundary groove profiles were analyzed from plane-view-oriented YSZ coatings progressively heat treated at $1000^{\circ}, 1100^{\circ}$, and $1200^{\circ} \mathrm{C}$. The same collection of grains was analyzed after every heat treatment for each of the three coatings. Peak-to-peak groove width measurements were obtained from cross-sectional topography profiles oriented perpendicular to the grain boundaries. Severely asymmetric grooves, polishing scratches, newly nucleated grains, and grains bordering pores or cracks were avoided in the measurement. Expected error for the groove-width measurements is dependent solely on image pixel resolution, as there is no error associated with tip geometry when measuring groove peak positions. ${ }^{18,19}$

Mullins's theories of grain-boundary grooving were used to determine the dominant diffusion mechanism at $1000^{\circ}, 1100^{\circ}$, and $1200^{\circ} \mathrm{C} .{ }^{13,14}$ For volume, surface, and evaporation/condensation diffusion, the theories prove the resulting groove profiles have groove widths $w$ proportional to annealing time $t^{1 / 3}, t^{1 / 4}$, and $t^{1 / 2}$, respectively. Klinger ${ }^{20}$ showed the changes in groove width with annealing time in a two-component system still follow the $t^{1 / 4}$ law for surface diffusion, as Mullins's original theories were for single component systems. Robertson ${ }^{21}$ and
Zhang and Schneibel ${ }^{22}$ have further extended the theories to include finite surface slopes beyond Mullins's assumption that the slope of the surface was small compared with unity. ${ }^{13,14}$

For the second AFM study, a cross-sectional-oriented YSZ coating was progressively heat treated from $1000^{\circ}$ to $1400^{\circ} \mathrm{C}$ for varying lengths of time to observe the evolution of interlamellar porosity and grain structure. The same lamella boundary was analyzed after each heat treatment. The AFM fast scan direction was perpendicular to the boundary to preserve height data after zero-order plane fitting was performed to remove the $z$-offset associated with AFM scans.

\section{(3) Dilatometric Study}

The shrinkage behavior in the axial direction of the YSZ coating tubes during $10 \mathrm{~h}$ isothermal holds from $800^{\circ}$ to $1400^{\circ} \mathrm{C}$ was investigated using a horizontal Orton ${ }^{B} 1600 \mathrm{D}$ dilatometer (Westerville, $\mathrm{OH}$ ). A heating rate of $10^{\circ} \mathrm{C} / \mathrm{min}$ was used for all tests. Length variations of the coatings were recorded using a linear variable displacement transducer (LVDT) capable of a resolution of $\pm 1 \mu \mathrm{m}$; however, the noise in the measurements because of temperature fluctuation was estimated to be $\pm 2 \mu \mathrm{m}$. The percent linear change recorded by the dilatometer reflects the thermal expansion of the apparatus, the thermal expansion of the coating, and the shrinkage of the coating. After isolating the data specific to the YSZ coating, the thermal expansion of the coating being tested was calculated as a function of temperature and subtracted from the raw data in order to obtain the data relative to the shrinkage of the YSZ. This step adds additional uncertainty to the final shrinkage measurements. Overall, the multiple sources of uncertainty limit the linear shrinkage resolution to approximately $\pm 0.1 \%$ for a $15 \mathrm{~mm}$ long sample.

\section{Results}

\section{(1) AFM Analysis of Plane-View-Oriented Samples}

The YSZ coating heat treated at $800^{\circ} \mathrm{C}$ for $10 \mathrm{~h}$ did not display any observable faceting or grain-boundary grooving. Average surface roughness for the measured images, calculated as a ratio of surface area to projected area, did not increase with heating. Notable surface features were limited to surface pores, surface cracks, and residual polishing scratches (not shown).

The $900^{\circ} \mathrm{C} / 10 \mathrm{~h}$ treated coating exhibited signs of early grain grooving. Grooving was non-uniform across the surface. Regions existed where grain boundary definition was insufficient to clearly outline entire grains. Some of the defined grain surfaces were more extensively roughened than others. Surface cracks and pores were observed.

Grain-boundary profiles of the same $9 \mu \mathrm{m}^{2}$ area of the planeview-oriented coating were analyzed after progressive heat treatments of $1,5,10,50$, and $100 \mathrm{~h}$ at $1000^{\circ} \mathrm{C}$. Grain-boundary grooves were sufficiently defined after the $1 \mathrm{~h}$ heat treatment to allow for accurate width measurements. As the 1 and $5 \mathrm{~h}$ images varied merely in contrast, only the area scans taken after the 10, 50, and $100 \mathrm{~h}$ treatments are displayed in Fig. 1(a). The previously polished surfaces of the grains became rough after annealing (see grain A, outlined in the first image of Fig. 1(a)). Surface roughening resulted in the formation of hills and valleys on the surfaces of the grains. Sometimes the roughened surfaces displayed clear striations (see grain B of Fig. 1(a)). The majority of grains exhibited various extents of surface roughening which coarsened with further annealing. Most grain-boundary groove profiles were also asymmetric.

Grains that displayed extensive surface roughening tended to groove at varying rates. Variable groove rates resulted in a range of groove widths observed within single grain boundaries and from one measured boundary to another; this will be subsequently referred to as non-uniform grooving. After the $1000^{\circ} \mathrm{C} /$ $50 \mathrm{~h}$ heat treatment, grains less than $60 \mathrm{~nm}$ in size, such as those identified by the box in the middle image of Fig. 1(a), seemed to disappear. A wide intralamellar microcrack spanning the $9 \mu \mathrm{m}^{2}$ analyzed area was exposed after the $100 \mathrm{~h}$ treatment. A larger 

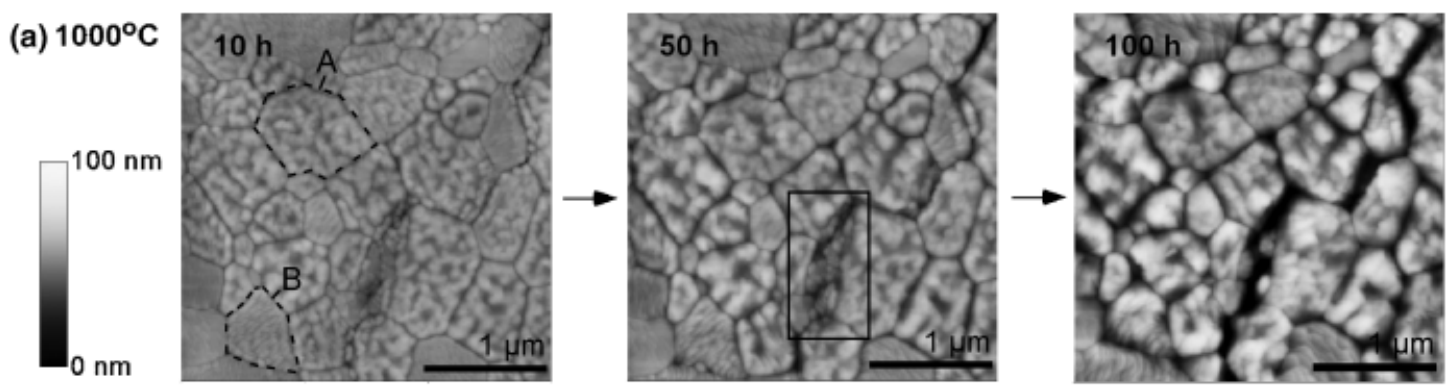

(b) $1100^{\circ} \mathrm{C}$
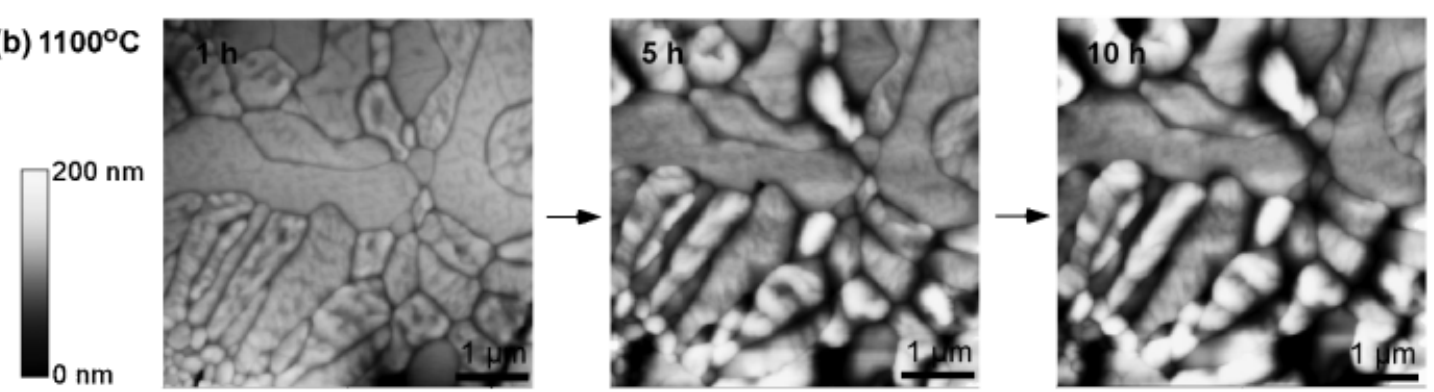

(c) $1200^{\circ} \mathrm{C}$
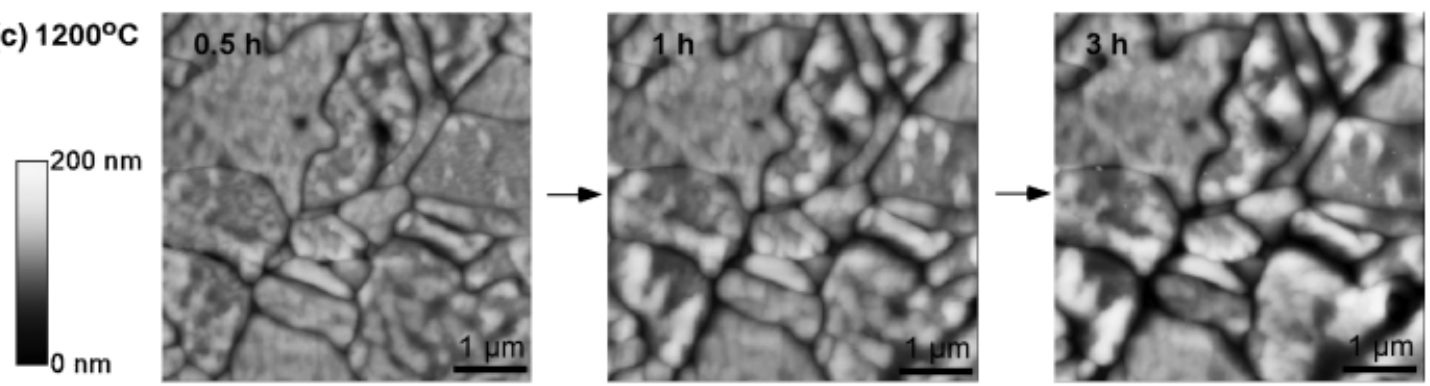

Fig. 1. Atomic force microscope area scans of plane-view oriented yttria-stabilized zirconia coatings annealed for different lengths of time at (a) $1000^{\circ} \mathrm{C}$, (b) $1100^{\circ} \mathrm{C}$, and (c) $1200^{\circ} \mathrm{C}$ illustrating the evolution of grain grooving, surface roughening, and grain growth/shrinkage. Contrast changes between the images at each temperature indicate changes in height. An example of the small grain disappearance discussed in the text is shown in (a): many grains present in the box of the $1000^{\circ} \mathrm{C} / 50 \mathrm{~h}$ image seem to be absent from the $100 \mathrm{~h}$ image.

area scan of the coating revealed the crack extended beyond the $9 \mu \mathrm{m}^{2}$ area and was clearly defined outside the analyzed area after the initial $1000^{\circ} \mathrm{C} / 1 \mathrm{~h}$ heat treatment.

Figure 1(b) displays the plane-view $25 \mu \mathrm{m}^{2}$ area scans of a coating progressively heat treated at $1100^{\circ} \mathrm{C}$ for 1,5 , and $10 \mathrm{~h}$. As shown in the lower left-hand corner of the images, after $1 \mathrm{~h}$, grains less than $200 \mathrm{~nm}$ in diameter began to decrease in size and coalesce with the surrounding grains. Surface roughening coarsened with annealing time. Non-uniform grain-boundary grooving and groove asymmetry were more prevalent at annealing temperatures of $1100^{\circ} \mathrm{C}$ than at $1000^{\circ} \mathrm{C}$ as the images in Fig. 1 demonstrate. Some grain boundaries grooved extensively between the 1 and $5 \mathrm{~h}$ treatments at $1100^{\circ} \mathrm{C}$, while other boundaries did not appear to change and therefore, were not measured. As non-uniform grooving amplified with time, analysis of the 50 and $100 \mathrm{~h}$ heat treatments was disregarded because of increasingly sporadic grooving.

Finally, grain grooving was studied from isothermal holds at $1200^{\circ} \mathrm{C}$ for $0.5,1$, and $3 \mathrm{~h}$ (analyzed scans shown in Fig. 1(c)). Decreased treatment times were used as the heightened temperature caused more extensive grooving in smaller periods of time than compared with the grooving observed at $1000^{\circ}$ and $1100^{\circ} \mathrm{C}$. Surface roughening coarsened with annealing time. Non-uniform grooving again led to a range of width measurements.

With annealing at all three temperatures, the average width of the grain-boundary grooves measured between each heat treatment increased with annealing time as shown by the $\log w-\log t$ plot in Fig. 2. Error bars indicated the range of observed groove widths. The $1000^{\circ} \mathrm{C}$ data in the plot displayed a linear curve fit with a slope similar to $1 / 4$, illustrating that surface diffusion was the dominant mechanism. The $\log w-\log t$ data from the $1100^{\circ} \mathrm{C}$ heat treatments had a curve-fit slope of 0.28 . When both surface and volume diffusion are taking place simultaneously, multiple works have concluded the slope corresponding to the $\log w-\log$ $t$ plot will be between $1 / 4$ (dominant surface diffusion) and $1 / 3$ (dominant volume diffusion). ${ }^{23,24}$ Thus, both surface and volume diffusion were active at $1100^{\circ} \mathrm{C}$. The linear curve fit of the $1200^{\circ} \mathrm{C} \log w-\log t$ data exhibited a slope equal to $1 / 3$, indicating

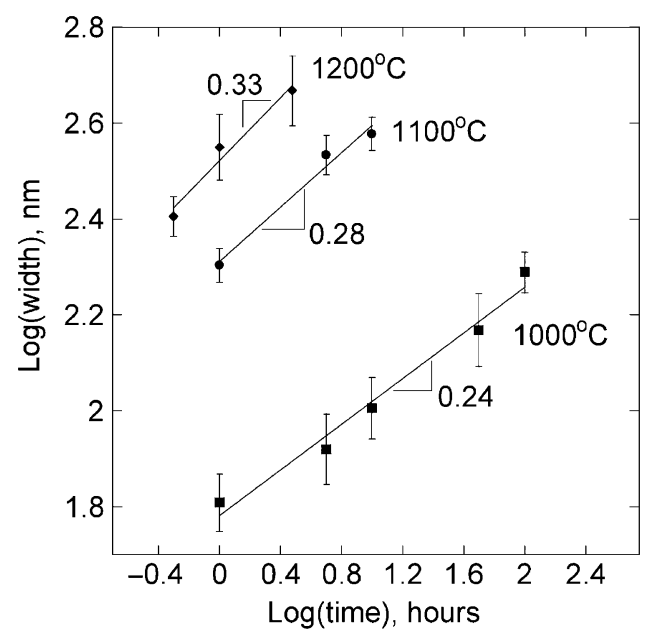

Fig. 2. Plot expressing the relationship between the grain-boundary groove widths as a function of annealing time at $1000^{\circ}, 1100^{\circ}$, and $1200^{\circ} \mathrm{C}$. The 0.24 slope of the linear curve fit for the $1000^{\circ} \mathrm{C}$ data indicates the dominant mass transport mechanism is surface diffusion. The 0.28 curve-fit slope of the $1100^{\circ} \mathrm{C}$ data indicates both volume and surface diffusion are active. The 0.33 curve-fit slope of the $1200^{\circ} \mathrm{C}$ data indicates volume diffusion is dominant. 
volume diffusion was the dominant transport mechanism at $1200^{\circ} \mathrm{C}$.

\section{(2) AFM Analysis of Cross-Sectional-Oriented Samples}

Figures 3(a)-(f) show the evolution of a single lamellar boundary during a progressive heat treatment at temperatures from

(a)

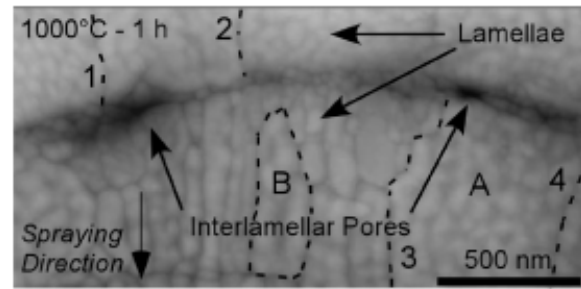

(b)

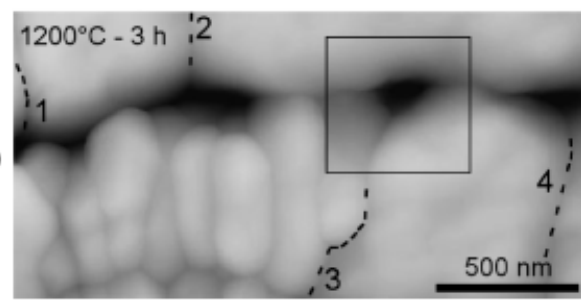

(c)

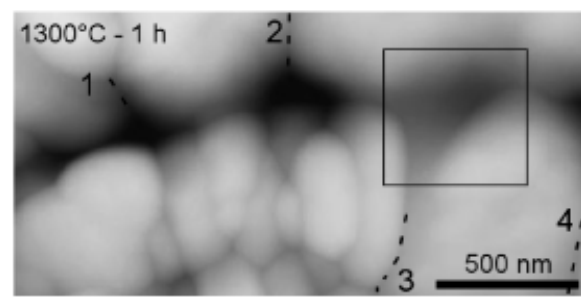

(d)

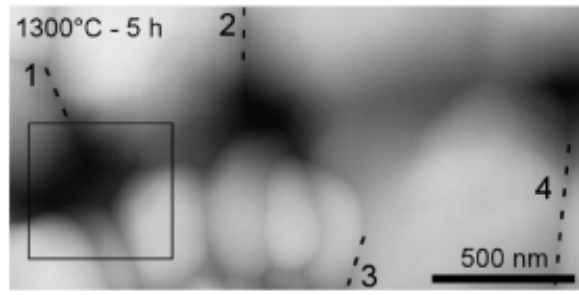

(e)

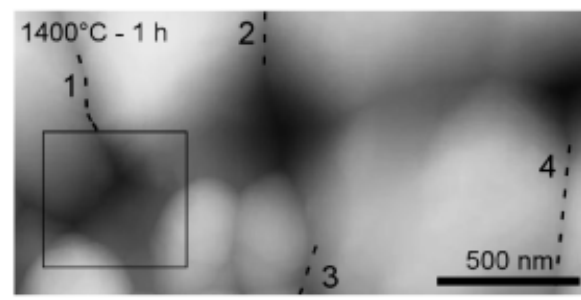

(f)

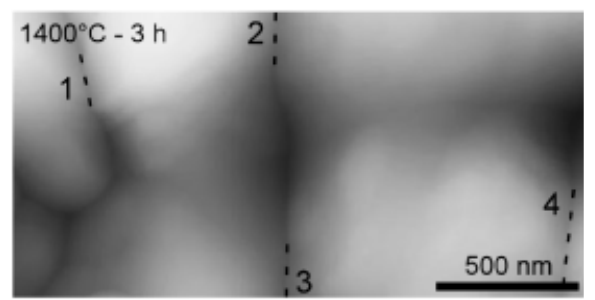

Fig. 3. Atomic force microscope area scans of one lamella boundary showing the evolution of the interlamellar porosity and grain structure of the boundary as the cross-sectional yttria-stabilized zirconia coating was progressively heat treated from $1200^{\circ}$ to $1400^{\circ} \mathrm{C}$. The same area was scanned each time. The same four grain boundaries are indicated by dotted lines and numbered 1-4 in each image to aid the reader in following the microstructural evolution. With increased annealing at higher temperatures, a number of changes occurred: the columnar grain structure grooved and coarsened; porosity became more spheroidal and segregated; and grains below the surface bridged the pore and ultimately sintered (as shown in the boxed areas). Contrast changes from black to white indicate a positive height change of $150 \mathrm{~nm}$ in image (a) and 400 $\mathrm{nm}$ in all other images. $1000^{\circ}$ to $1400^{\circ} \mathrm{C}$. The same four-grain boundaries are indicated with dotted lines and numbered in all the images to aid the reader in observing the evolution of the region. Heat treating commenced at $1000^{\circ} \mathrm{C}$ for $1 \mathrm{~h}$ to allow for uniform grain definition across the coating.

Figure 3(a) shows the single lamella boundary targeted throughout the analysis after the $1000^{\circ} \mathrm{C} / 1 \mathrm{~h}$ heat treatment. The area between grain boundary \#3 and \#4 comprises one columnar grain approximately $600 \mathrm{~nm}$ in width and labeled grain A. The surface of grain A displayed extensive surface roughening. A number of smaller columnar grains (roughly 100-200 nm in width) existed to the left of grain A (see grain B in Fig. 3(a)). These grains also displayed surface roughening, though due to the decreased size of the grains, the roughening was more difficult to resolve than the roughening present on grain $\mathrm{A}$. The structure of the columnar grains coarsened ${ }^{25}$ with further annealing at temperatures of $1200^{\circ} \mathrm{C}$ and above as shown in Figs. 3(b-f): existing grains enlarged at the expense of smaller grains during each heat treatment. The surface roughening observed after the $1000^{\circ} \mathrm{C} / 1 \mathrm{~h}$ treatment in Fig. 3(a) was also observed to decrease at temperatures of $1200^{\circ} \mathrm{C}$ and above.

After $1 \mathrm{~h}$ at $1300^{\circ} \mathrm{C}$ (Fig. 3(c)), sintering across the interlamellar pores was observed which caused the pores to become more spheroidal and segregated. This densification resulted from grain grooving directed across the pore at depths below the exposed surface grains. The bridging grain (outlined by the boxes in Figs. 3(b) and (c)) existed at a depth below the surface grains. Bridging from below was further verified from the $1400^{\circ} \mathrm{C} / 1 \mathrm{~h}$ scan: as indicated by the boxes in Figs. 3(d) and (e), a surface grain merged with the grain beneath, which was responsible for closing the pore. The interlamellar pores further healed after the $1400^{\circ} \mathrm{C} / 3 \mathrm{~h}$ treatment (Fig. 3(f))

\section{(3) Dilatometer Studies}

Figure 4 is a plot of the shrinkage behavior of YSZ coatings as a function of time at different test temperatures. No shrinkage of the YSZ was detected after $10 \mathrm{~h}$ at $800^{\circ}$ or $900^{\circ} \mathrm{C}$. Approximately $0.08 \%$ linear shrinkage was measured after $1000^{\circ} \mathrm{C} / 10 \mathrm{~h}$ trial, which was believed to be bordering on the resolution limits of the apparatus. Greater linear shrinkages were observed for similar isothermal trials at $1100^{\circ}, 1200^{\circ}, 1300^{\circ}$, and $1400^{\circ} \mathrm{C}$. The amount of shrinkage after the $1200^{\circ} \mathrm{C} / 10 \mathrm{~h}$ trial doubled compared with the $1100^{\circ} \mathrm{C} / 10 \mathrm{~h}$ trial. Similarly, after $10 \mathrm{~h}$ at $1300^{\circ} \mathrm{C}$, the amount of measured shrinkage was twice that of samples heat treated for $10 \mathrm{~h}$ at $1200^{\circ} \mathrm{C}$. Some shrinkage occurs during heat-up of the coating at testing temperatures greater than $1100^{\circ} \mathrm{C}$; thus, some linear shrinkage of the coating has already occurred when the isothermal hold begins.

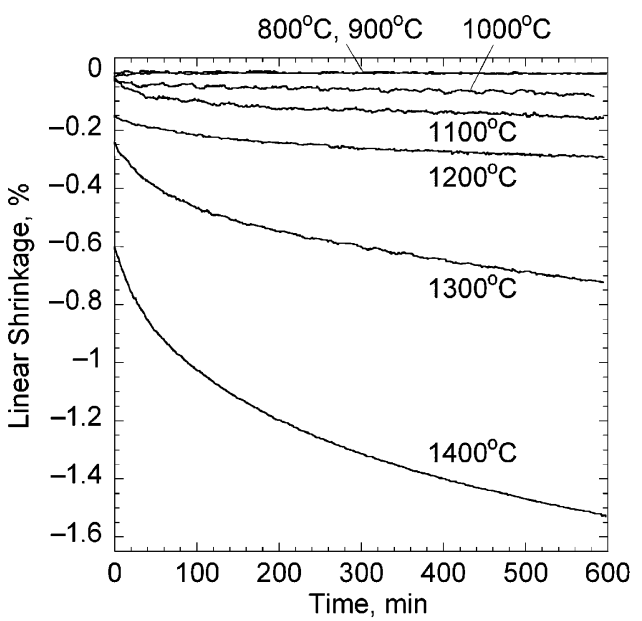

Fig. 4. A plot of the linear dilatometry response of yttria-stabilized zirconia coatings tested at different temperatures showing the shrinkage behavior of the coatings as a function of time. 


\section{Discussion}

\section{(1) Microstructural Changes from $800^{\circ}$ to $1000^{\circ} \mathrm{C}$}

As discussed in the introduction, Trice et al. ${ }^{6}$ and Ilavsky et al. ${ }^{12}$ observed the disappearance of intralamellar cracks in fused and crushed YSZ coatings annealed at $1000^{\circ} \mathrm{C}$. Here, surface diffusion was found to be the dominant diffusion mechanism at $1000^{\circ} \mathrm{C}$, indicating the crack disappearance reported in the literature was the result of a non-densifying mass transport mechanism. ${ }^{26}$ Dilatometry results further confirmed this conclusion as no appreciable shrinkage was detected until the $10 \mathrm{~h}$ isothermal hold at $1100^{\circ} \mathrm{C}$.

There is evidence in the literature supporting surface diffusion as the dominant mass transport mechanism in zirconia at relatively low temperatures. In a study using pore smoothing observations and particle neck growth measurements by Akash and Mayo, ${ }^{27}$ surface diffusion was shown to be the dominant mass transport mechanism in tetragonal $3 \mathrm{~mol} \% \mathrm{Y}_{2} \mathrm{O}_{3}-\mathrm{ZrO}_{2}$. Evidence of $\mathrm{Zr}^{4+}$ ion transport to the neck between spherical powders was observed at temperatures from $870^{\circ}$ to $1050^{\circ} \mathrm{C}$. In situ transmission electron microscope experiments at $890^{\circ} \mathrm{C}$ also noted surface diffusion was the likely transport mechanism for pore smoothing between nanocrystalline grains of zirconia. ${ }^{28}$

Since surface diffusion is a non-densifying transport mechanism, this mechanism can only change the shape of an isolated intralamellar crack. However, narrow intralamellar cracks connected to interlamellar pores would completely heal; atoms present on the surface of the pore would diffuse in the direction of decreased chemical potential ${ }^{25}$ and fill the crack. As densification is not occurring, the decrease in volume of the crack would be balanced by an increase in volume of the pore. If the intralamellar crack is not coupled with an interlamellar pore, the crack could not heal in the traditional sense but become spheroidal. Allen et al. ${ }^{4}$ suggested intralamellar cracks in annealed coatings tended to form globular or irregular-shaped pores during a study of plasma-sprayed YSZ coatings made with fused and crushed 7-8 wt\% YSZ powder. Evidence of spheroidal intralamellar cracks was not observed on AFM images, but the small volume of such defects in the process of healing might make observation difficult.

Another noteworthy microstructural change was the development of surface roughening on the exposed grains. AFM analysis of the plane-view coatings showed different extents of surface roughening existed on the surfaces of the grains after annealing. Roughening coarsened with increased annealing time during the $1000^{\circ} \mathrm{C}$ progressive heat treatment. Surface roughening was also observed on the cross-sectional coating after the $1000^{\circ} \mathrm{C} / 1 \mathrm{~h}$ heat treatment.

Non-uniform grooving and asymmetric grain-boundary grooves were frequently observed from the AFM analysis of the annealed coatings. Robertson and Chang ${ }^{29}$ concluded variations of the surface diffusion coefficient with orientation will lead to non-uniform grooving and the formation of asymmetric grooves. Multiple studies support this conclusion. ${ }^{30-32}$ Thus, the surface roughening observed during the AFM analysis of the annealed YSZ coatings was most likely due to surface diffusivity anisotropy. The diffusion variations may be induced by crystallographic faceting from surface energy anisotropy ${ }^{31,33}$ of the plasma-sprayed coating or a heterogeneous composition across the surface of the coating. ${ }^{34}$ The distribution of yttrium atoms within the lamellar microstructure depends on the interface morphology adopted during solidification. ${ }^{35}$ By modeling the heat transfer and solidification of plasma-sprayed YSZ splats, Wang et $\mathrm{al}^{35}$ showed that poor heat transfer during solidification results in low solidification interface velocity which can lead to microsegregation of yttria at grain or dendrite boundaries. Regarding the validity of Mullins's surface diffusion theories in the presence of surface roughening and faceting, Sachenko et $a l^{31}$ showed unfaceted grains and faceted grains that coarsened with further annealing remained in qualitative agreement with Mullins's theories. The validity of the theories was also unaffected by the presence of asymmetric grain-boundary grooves.
The driving force behind the exposure of the wide microcrack after the plane-view $1000^{\circ} \mathrm{C} / 100 \mathrm{~h}$ heat treatment (shown in Fig. 1(a)) remains to be understood. No evidence of coating densification was observed from the AFM plane-view images presented in Fig. 1. The dilatometer was also unable to detect significant shrinkage with annealing at $1000^{\circ} \mathrm{C}$. As the planeview region analyzed was small relative to the bulk volume of the annealed coating, it was believed the morphological evolution at the surface was effectively constrained by the interior grains. Sudre and Lange ${ }^{36}$ studied the breakup of grain bridges within polycrystalline $8 \mathrm{~mol} \% \mathrm{Y}_{2} \mathrm{O}_{3}-\mathrm{ZrO}_{2}$ compacts resulting in the formation of "large cracklike voids." When the distance between particle centers remains constant in a three-grain bridge (similar to the small grains present between the larger grains in the box of Fig. 1(a)), it is possible for the necking region to become unstable, causing the larger grains to desinter from the smaller, center grains in order to reduce the free energy of the system. Rankin and Boatner ${ }^{37}$ also observed the desintering of single-crystal $\mathrm{MgO}$ particles when surface diffusion was the likely mass transport mechanism in the system. As the AFM images alone do not yield enough information about the factors which may have caused desintering by destabilizing the coating (such as the existence of a porosity gradient within the coating or the coarsening of smaller grains within the neck ${ }^{37}$ ), a more in-depth analysis is needed.

\section{(2) Microstructural Changes from $1100^{\circ}$ to $1400^{\circ} \mathrm{C}$}

As shown in the AFM images of Fig. 3, thermal grooving resulted in columnar grains assuming a rounded appearance at the pore interface, able to bridge interlamellar pores. Grain bridging was favorable at temperatures of $1200^{\circ} \mathrm{C}$ and above. The images also revealed the bridging grains would ultimately come into contact and sinter during heat treatments of $1300^{\circ}$ and $1400^{\circ} \mathrm{C}$, healing the interlamellar pores.

As observed in the cross-sectional AFM study, the interlamellar pores appeared to enlarge between the $1000^{\circ} \mathrm{C} / 1 \mathrm{~h}$ and $1200^{\circ} \mathrm{C} / 3 \mathrm{~h}$ heat treatments (Figs. 3(a) and (b), respectively). This pore widening was due to the grooving of surrounding grains. Consistent with the plane-view AFM study and thermal grooving theories, with increased annealing the columnar grains exposed at the polished surface grooved rapidly and increased in height above the original surface height of the coating. Thus, mass was being removed from the upper walls of the pores and redistributed, creating the illusion of pore expansion at the surface. Below the surface, thermal grooving experienced by grains would only have taken place along the pore interface as the surrounding grains would have constrained growth in all other directions. This idea of constrained, directed grooving explains why the bridging and healing of the pores initiated below the outer surface grains as observed in the cross-sectional study.

Densification of the coating was driven by volume diffusion, shown to be the competing and dominant transport mechanism in the coatings at $1100^{\circ}$ and $1200^{\circ} \mathrm{C}$, respectively. At temperatures above $1200^{\circ} \mathrm{C}$, volume diffusion remained the dominant transport mechanism as the reduction in porosity and resulting shrinkages detected by the dilatometer at $1300^{\circ}$ and $1400^{\circ} \mathrm{C}$ could not result from either surface or evaporation/condensation diffusion mechanisms. Diffusion along the grain boundaries (limited by the slowest diffusing species: $\mathrm{Zr}^{+4}$ ions ${ }^{27}$ ) was most likely occurring as opposed to lattice diffusion due to the large grain-boundary area relative to the bulk volume of the coatings. ${ }^{26}$ The rate of shrinkage (represented by the first derivative of the curves in Fig. 4) decreased with time as the interlamellar pores became spheroidal and/or healed, reducing the total interfacial energy of the system and thus, reducing the driving force for sintering. ${ }^{38}$ Shrinkage rates remained non-zero for the duration of the test for coatings treated at or above $1100^{\circ} \mathrm{C}$, indicating densification would continue at these temperatures.

Surface roughening coarsened with increased annealing time (as seen in Figs. 1(a)-(c) from the AFM plane-view analysis) and disappeared with increased annealing temperature (as seen in 
Figs. 3(a)-(f) from the cross-sectional analysis). Surface roughening was previously described as being a collection of hills and valleys. Similar to the driving force behind grain grooving, the hill-and-valley morphology created chemical potential gradients across the surface of the grain. ${ }^{25}$ Atomic diffusion became more active with heightened annealing temperatures, allowing for the redistribution of atoms from the hills (high chemical potential) to the valleys (low chemical potential), eliminating the surface roughening and lowering the related interfacial energy. ${ }^{38}$

The results of this present work enable the TBC scientific community to take a closer look at the phenomena behind coating densification, leading to decreased durability and performance of TBCs. As mentioned earlier, ${ }^{12}$ previous findings link the low- and high-temperature sintering regimes to the size and shape differences of the voids. Though the atomic migration causing sintering does depend on size and shape differences (leading to chemical potential gradients, for example), this study finds that the dominance of two distinctly different diffusion mechanisms is responsible for the void reductions at the various temperatures. By directly identifying the dominant mechanisms, future research can investigate ways of impeding or controlling the mechanisms leading to coating densification. For example, the temperature at which volume diffusion and densification becomes significant may be increased by the addition of impurities or altered plasma-spraying parameters and feedstock (leading to different microstructural characteristics).

\section{Summary}

Plasma-sprayed TBCs have low thermal conductivity, owed in part to the highly porous microstructure. It has been recognized previously that the densification of the coatings with prolonged exposure to high temperatures will lead to increases in thermal conductivity. This research is aimed at improving coating durability and performance by a thorough investigation of the mechanisms responsible for the microstructural changes causing the conductivity increase.

With increased annealing temperatures and times, the microstructure of the plasma-sprayed YSZ coatings was observed to coarsen and sinter. The surface roughening, non-uniform grain grooving, and the formation of asymmetric grooves observed at temperatures of $900^{\circ} \mathrm{C}$ and above was most likely because of surface diffusivity anisotropy. Surface roughening coarsened with increased annealing time and disappeared with increased annealing temperatures. Changes in porosity began with the disappearance of narrow intralamellar microcracks at $1000^{\circ} \mathrm{C}$. Application of Mullins's thermal grooving theories and AFM measurements of the same collection of grains after successive heat treatments revealed surface diffusion was the dominant diffusion mechanism at $1000^{\circ} \mathrm{C}$. Thus, intralamellar cracks were eliminated via a non-densifying mass transport mechanism, either by atoms of a connected pore filling the crack or by the shape of the crack becoming spheroidal. Overall, the total volume attributed to voids in the coatings would not change.

Interlamellar pores closed at annealing temperatures of $1200^{\circ} \mathrm{C}$ and above. Surrounding columnar grains were able to bridge the widths of the voids and come into contact, sintering with other bridging grains. Volume diffusion was found to be the dominant mass transport mechanism at $1200^{\circ} \mathrm{C}$. This result was confirmed by the appreciable shrinkages observed by the dilatometer, indicating volume diffusion dominated above $1200^{\circ} \mathrm{C}$ as well.

\section{References}

${ }^{1}$ R. B. Heimann, Plasma-Spray Coating: Principles and Applications, pp. 164 165, 209-23. VCH, Weinheim, Germany, 1996.

${ }^{2}$ R. A. Miller, "Current Status of Thermal Barrier Coatings - An Overview," Surf. Coat. Technol., 30, 1-11 (1987).

${ }^{3}$ R. McPherson, "A Review of Microstructure and Properties of PlasmaSprayed Ceramic Coatings," Surf. Coat. Tech., 39/40, 173-81 (1989).

${ }^{4}$ A. J. Allen, J. Ilavsky, G. G. Long, J. S. Wallace, C. C. Berndt, and H. Herman, "Microstructure Characterization of Yttria-Stabilized Zirconia Plasma-
Sprayed Deposits Using Multiple Small-Angle Neutron Scattering," Acta Mater., 49, 1661-75 (2001).

${ }^{5}$ T. Chraska and A. H. King, "Growth of Columnar Grains During ZirconiaYttria Splat Solidification,” J. Mater. Sci. Lett., 18, 1517-9 (1999).

${ }^{6}$ R. W. Trice, Y. J. Su, J. R. Mawdsley, K. T. Faber, A. R. De Arellano-López, H. Wang, and W. D. Porter, "Effect of Heat Treatment on Phase Stability, Microstructure, and Thermal Conductivity of Plasma-Sprayed YSZ," J. Mater. Sci., 37, 2359-65 (2002)

${ }^{7}$ R. McPherson, "Relationship Between the Mechanism of Formation, Microstructure and Properties of Plasma-Sprayed Coatings," Thin Solid Films, 83 [3] 297-310 (1981).

${ }^{8}$ L. Lelait, S. Alperine, C. Diot, and M. Mevrel, “Thermal Barrier Coatings: Microstructural Investigation After Annealing," Mater. Sci. Eng. A, A121, 475-82 (1989).

${ }^{9}$ K. Muraleedharan, J. Subrahmanyam, and S. B. Bhaduri, "Identification of t' Phase in $\mathrm{ZrO}_{2}-7.5 \mathrm{wt} \% \mathrm{Y}_{2} \mathrm{O}_{3}$ Thermal-Barrier Coatings," J. Am. Ceram. Soc., 71 [5] C226-7 (1988).

${ }^{10}$ H. G. Scott, "Phase Relationships in the Zirconia-Yttria Systems," J. Mater. Sci., 10 [9] 1527-35 (1975).

${ }^{11}$ S. R. Choi, D. Zhu, and R. A. Miller, Effects of Sintering on Mechanicals and Physical Properties of Plasma-Sprayed Thermal Barrier Coatings. John H. Glenn Research Center, Cleveland, OH, 2004.

${ }^{12}$ J. Ilavski, G. G. Long, A. J. Allen, and C. C. Berndt, "Evolution of the Void Structure in Plasma-Sprayed YSZ Deposits During Heating," Mater. Sci. Eng., A272, 215-21 (1999).

${ }^{13}$ W. W. Mullins, "Theory of Thermal Grooving," J. Appl. Phys., 28 [3] 333-9 (1957)

${ }^{14}$ W. W. Mullins, "Grain Boundary Grooving by Volume Diffusion," AIME Trans., 218, 354-61 (1960).

${ }^{15}$ G. R. Dickinson, C. Petorak, K. Bowman, and R. W. Trice, "Stress-Relaxation of Compression Loaded Plasma-Sprayed $7 \mathrm{wt} \% \quad \mathrm{Y}_{2} \mathrm{O}_{3}-\mathrm{ZrO}_{2}$ Stand-Alone Coatings," J. Am. Ceram. Soc., 88 [8] 2202-8 (2005).

${ }^{16}$ C. Deschaseaux, "A Sintering Study of Plasma-Sprayed Yttria Stabilized Zirconia Thermal Barrier Coatings Using Stand-Alone Coating Tests." Master's Thesis, Purdue University, West Lafayette, IN, 2002.

${ }^{17}$ T. F. Bernecki and D. R. Marron, "Small Particle Plasma Spray Apparatus, Method and Coated Article." U.S. Patent No. 5,744,777, April 28, 1998.

${ }^{18}$ D. M. Saylor and G. S. Rohrer, "Measuring the Influence of Grain-Boundary Misorientation on Thermal Groove Geometry in Ceramic Polycrystals," J. Am Ceram. Soc., 82 [6] 1529-36 (1999).

${ }^{19}$ E. Saiz, R. M. Cannon, and A. P. Tomsia, "Energetics and Atomic Transport at Liquid Metal $/ \mathrm{Al}_{2} \mathrm{O}_{3}$ Interfaces," Acta Mater., 47 [15] 4209-20 (1999).

${ }^{20}$ L. Klinger, "Surface Evolution in Two-Component System," Acta Mater., 50, 3385-95 (2002).

${ }^{21}$ W. M. Robertson, "Grain-Boundary Grooving by Surface Diffusion for Finite Surface Slopes,” J. Appl. Phys., 42 [1] 463-7 (1971).

${ }^{22}$ W. Zhang and J. H. Schneibel, "Numerical Simulation of Grain-Boundary Grooving by Surface Diffusion," Comp. Mater. Sci., 3, 347-58 (1995).

${ }^{23}$ W. M. Robertson and S. R. Srinivasan, "Interpretation of Grain Boundary Grooving Data for Combined Surface and Volume Diffusion," Met. Trans. A., 6A, 1653-4 (1975)

${ }^{24}$ W. M. Robertson, "Thermal Etching and Grain-Boundary Grooving of Silicon Ceramics," J. Am. Ceram. Soc., 64 [1] 9-13 (1981).

${ }^{25}$ Y.-M. Chiang, D. P. Birnie III, and W. D. Kingery, Physical Ceramics: Principles for Ceramic Science and Engineering, pp. 357-88. John Wiley \& Sons Inc., New York, 1997.

${ }^{26}$ S-J. L. Kang, Sintering: Densification, Grain Growth \& Microstructure, pp. 37-87. Elsevier Butterworth-Heinemann, Burlington, MA, 2005

${ }^{27}$ Akash and M. J. Mayo, "Zr Surface Diffusion in Tetragonal Yttria Stabilized Zirconia," J. Mater. Sci., 35 [2] 437-42 (2000).

${ }^{28}$ J. Rankin and B. W. Sheldon, "In situ TEM Sintering of Nano-Sized $\mathrm{ZrO}_{2}$ Particles," Mater. Sci. Eng. A., A204, 48-53 (1995).

${ }^{29}$ W. M. Robertson and R. Chang, "Chapter 4: The Kinetics of Grain-Boundary Groove Growth on Alumina Surfaces"; pp. 49-60 in Materials Science Research, Vol. 3: The Role of Grain Boundaries and Surfaces in Ceramics, Edited by W. W. Kriegel and H. Palmour III. Plenum Press, New York, 1966.

${ }^{30}$ E. Rabkin and L. Klinger, "The Fascination of Grain Boundary Grooves," Adv. Eng. Mater., 3 [5] 277-82 (2001).

${ }^{31}$ P. Sachenko, J. H. Schneibel, and W. Zhang, "Effect of Faceting on the Thermal Grain-Boundary Grooving of Tungsten," Philos. Mag. A., 82 [4] 815-29 (2002).

${ }^{32}$ E. Rabkin, Y. Amouyal, and L. Klinger, "Scanning Probe Microscopy Study of Grain Boundary Migration in NiAl," Acta Mater., 52, 4953-9 (2004).

${ }^{33}$ C. A. Handwerker, J. M. Dynys, R. M. Cannon, and R. L. Coble, "Dihedral Angles in Magnesia and Alumina: Distributions from Surface Thermal Grooves," J. Am. Ceram. Soc., 73 [5] 1371-7 (1990).

${ }^{34}$ Y.-M. Chiang, D. P. III Birnie, and W. D. Kingery, Physical Ceramics: Principles for Ceramic Science and Engineering, p. 186. John Wiley \& Sons, Inc., New York, 1997.

${ }^{35}$ G.-X. Wang, R. Goswami, S. Sampath, and V. Prasad, "Understanding the Heat Transfer and Solidification of Plasma-Sprayed Yttria-Partially Stabilized Zirconia Coatings," Mater. Manuf. Processes, 19 [2] 259-72 (2004).

${ }^{36}$ O. Sudre and F. F. Lange, "The Effect of Inclusions on Densification: III, The Desintering Phenomenon," J. Am. Ceram. Soc., 75 [12] 3241-51 (1992).

${ }^{37}$ J. Rankin and L. A. Boatner, "Unstable Neck Formation During Initial-Stage Sintering," J. Am. Ceram. Soc., 77 [8] 1987-90 (1994).

${ }^{38}$ S-J. L. Kang, Sintering: Densification, Grain Growth \& Microstructure, pp. 1-36. Elsevier Butterworth-Heinemann, Burlington, MA, 2005. 